\title{
Evaluating the Landscape Capacity of Protected Rural Areas to Host Photovoltaic Parks in Sicily
}

\section{Laura Carullo, Patrizia Russo, Lara Riguccio, Giovanna Tomaselli}

Department of Agri-Food and Environmental Systems Management, Catania University, Catania, Italy. Email: lauracarullo@gmail.com,patrusso@unict.it,riguccio@unict.it, gitomas@unict.it

Received August 25 $5^{\text {th }}, 2013$; revised October $3^{\text {rd }}, 2013$; accepted October $30^{\text {th }}, 2013$

Copyright (C) 2013 Laura Carullo et al. This is an open access article distributed under the Creative Commons Attribution License, which permits unrestricted use, distribution, and reproduction in any medium, provided the original work is properly cited.

\begin{abstract}
This paper uses the LCA (Landscape Character Assessment) manuals produced by the Countryside Agency and Scottish Natural Heritage to develop a method for analysing the characteristics of the landscape and its ability to host photovoltaic parks. The method was tested on a site which is part of the Natura 2000 network in Sicily, where the different needs of high quality agricultural land, scenery of great natural value and human activities compete with one another. The evaluation of the landscape's capacity to absorb the changes was effectuated by defining criteria which take into consideration the possible impact of photovoltaic sites on the landscape. These criteria were used to evaluate the sensitivity of the characteristics of the landscape as well as its quality and value, and the visual impact of the proposed changes. Most of the Landscape Units were found to be not suitable for photovoltaic parks because of the high value of the land. However, protected agricultural land, mainly used for greenhouses, has a medium to high capacity to host photovoltaic plants, and if these are correctly planned, this could help to lower the sensitivity levels.
\end{abstract}

Keywords: Natural Resources; Energy Resources; Landscape Resources

\section{Introduction}

There is increasing interest in developing photovoltaic energy in Sicily. The statistical institute GSE (Gestore Servizi Energetici-management of electrical services) found that photovoltaic energy production increased from 155.9 MW in 2010 to $865.7 \mathrm{MW}$ in 2011 , and $60 \%$ of this was produced from land sites [1].

While the energy, economic and environmental impact of photovoltaic plants is generally seen as positive [2-4], the large scale use has a negative impact on the landscape, particularly in rural areas.

At national level, photovoltaic energy and other renewable energy sources are encouraged, but local communities are more concerned about their negative impact on their quality of life and the landscape [5].

Consequently, landscape aspects have taken on a key role in determining the new sustainable energy strategy [6].

Scientific studies have mainly considered the general impact of photovoltaic farms on the landscape [7-9] although deeper research has also concentrated on the visual impact $[10,11]$. However, the visual and perceptual impact of solar parks on the landscape is similar to that of other structures, such as wind farms, greenhouses, warehouses, etc. There is a great deal of literature on this argument, with useful information on the best way to limit their visual impact [12-22].

However, analysing the impact of a project depends on assessing its visual impact on the site. This requires a landscape plan which can resolve the contradictions involved in defining the assets of the landscape, and thus it not only mitigates the impact on the landscape but also ensures that the plants themselves contribute to its quality and identity, and respect the character of the place [12].

The site was studied during the drafting of the Management Plan for the area.

The SCI/SPA sites of the Natura 2000 network are areas that the European Directives 43/92/CEE "Habitat" and 409/79/CEE "Birds" state are important for guaranteeing the conservation of biodiversity, the habitats, and the species, as part of a European Union wide network of ecological sites. These sites also host normal human activities, and this needs to be taken into consideration when developing strategies for protecting and improving their natural resources (Art. 2) [23-25]. 
This is one of the fundamental principles established for the landscape by the European Landscape Convention [26], i.e. that conservation and planning measures are only effective if they are established with the consensus and participation of the local population.

Thus, it is necessary to study how to reconcile conservation needs with social and economic development, and with protecting the landscape.

The sites of Natura 2000 network include some exceptional landscape that should be preserved and also some ordinary landscape and degraded areas. The latter needs to be managed and recovered, so that they can become places of "varied" quality, useful for everyday activities. Planning allows us to reach these objectives, and this is based on observation, evaluation and interpretation of the dynamics of the landscape. Unlike other landscapes, "protected" areas, "are distinguishable by having greater (potential) operational efficacy, due to the existence of a management plan, special management, and a management structure, finance being available, and, in some cases, consolidated experience built up over years..." $[25,27]$. This means that in some cases they can become experimental laboratories for innovative policies for sustainable development and "model" examples of land management. This is also true when the question of inserting photvoltaic parks is considered, in some cases they may be compatible with the objectives of Natura 2000.

This work elaborates criteria for deciding which rural areas are best suited for photovoltaic parks, taking into consideration respect for the local character and the cultural, social and production changes that would ensue. A methodology for analysing and evaluating the landscape was created and its validity tested on a sensitive rural area which is part of the Italian Natura 2000 network: the SCI-SPA "Torre Manfria, Biviere di Gela, Piana di Gela" site, on the southern coast of Sicily. Parts of the area have suffered greatly from human activities.

The area under investigation is dedicated to conserving nature, and in particular migratory birds, and this would logically exclude the installation of photovoltaic parks. The parks could, however, be installed in certain degraded landscape in the area without interfering with the above objectives.

\section{Materials and Methods}

This work evaluates the capacity of the SCI/SPA "Torre Manfria, Biviere di Gela, Piana di Gela" to host photovoltaic parks, following the guidelines laid out in the LCA (Landscape Character Assessment) manuals.

SCI/SPA "Torre Manfria, Biviere di Gela, Piana di Gela" is a site of great natural value and includes an internationally important wetland (Ramsar) where both local and migratory birds winter, nest and live. It is a fundamentally important ecological unit for flora $[28,29]$ and fauna [30] (Figure 1).

It has a surface area of $178.4656 \mathrm{~km}^{2}$, including marine areas. The land area is $160.28 \mathrm{~km}^{2}$, which is equivalent to $3.6 \%$ of the total surface area of the regional Natura 2000 network.

The vast areas of wetland, in particular the "Biviere di Gela", a regional conservation area and Ramsar site, mean that the site is of marked importance for bird conservation. It also contains areas of cereal crops.

Along the coast the vegetation is host to a myriad of habitats and home of many types of fauna [31].

There is also highly visible human activity with great environmental impact, but also areas of marked historical and archaeological value and active productive land. All of these coexist in a way which is not consistent with the definitions for areas classified as IBA (Important Bird Areas) [32].

The evaluation uses the information on landscape units (LU) obtained in a previous paper. Their characteristics are shown in Table 1, and their geographical location and borders are shown in Figure 2 [32-36].

The LCA manual, and its later expansion [37], defines landscape capacity as "the degree to which a particular landscape character type or area is able to accommodate change without significant effects on its character". This capacity changes, depending on the types of the proposed changes, and does not establish precise limits to landscape transformation, but rather defines the potential areas which can host the changes [38,39].

It is worth clarifying that a state or regionally protected landscape is not necessarily a highly sensitive landscape. The capacity depends on the relationships between the value of the landscape, its sensitivity, and the type of proposed changes. This is the reason why a high value landscape may not be compromised by a particular

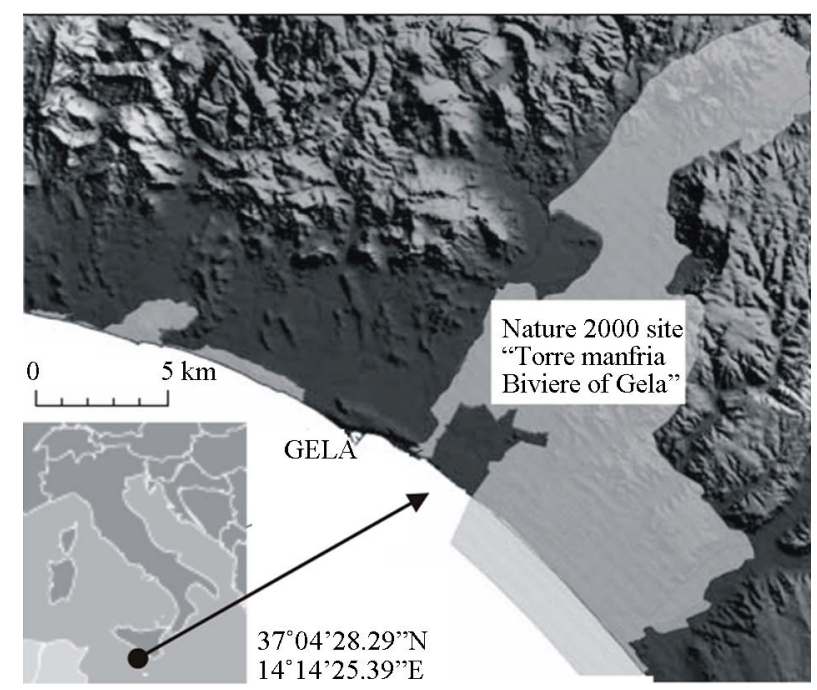

Figure 1. Study area. 
Table 1. Description of features for Landscape Units identified.

\begin{tabular}{|c|c|}
\hline Landscape Units & Description of features \\
\hline LU 1. Mount Ursitto & $\begin{array}{l}\text { Chalky-sulphuric rugged outcrops subject to high erosion, steep slopes. Scrub and small olive groves or vineyards. Markedly } \\
\text { unspoilt nature. }\end{array}$ \\
\hline $\begin{array}{l}\text { LU 2. Ursitto Sottano } \\
\text { and Serralunga }\end{array}$ & Undulating morphology of clay or fluvial deposits. Cultvated land with many almond orchards and olive groves. \\
\hline $\begin{array}{l}\text { LU 3. Muro Rizzo Plain } \\
\text { and Lenze of Budiciano }\end{array}$ & $\begin{array}{l}\text { Morphological plain, crossed by the river Maroglio, the main tributary of the river Gela. The area is divided into regular fields } \\
\text { with small farm buildings. }\end{array}$ \\
\hline LU 4. Gela Plain & $\begin{array}{l}\text { A wide plain, rich in water and fertile, cultivated almost exclusively for artichokes. Niscemi's high plains are like leaning high } \\
\text { buttresses to the plain crossed by river Gela and its tributaries, the Maroglio and Cimia. The estuary area has been urbanized } \\
\text { with houses and other services and communication infrastructure. }\end{array}$ \\
\hline LU 5. Niscemi Ravines & $\begin{array}{l}\text { An extensive ravine system set among clay hills. It is accessible by tracks which provide a panoramic view of Gela's entire } \\
\text { plain, down to the sea. }\end{array}$ \\
\hline $\begin{array}{l}\text { LU 6. Hillside Valleys } \\
\text { of the Valle Torta and } \\
\text { Valle Priolo Rivers }\end{array}$ & $\begin{array}{l}\text { Clayey hills and mainly torrent-like streams. Mainly a farming area with, almond orchards, olive groves and vineyards as well } \\
\text { as tilled land. Much greenhouse cultivation especially in the higher central area. }\end{array}$ \\
\hline $\begin{array}{l}\text { LU 7. Plain of the } \\
\text { DirilloRiver }\end{array}$ & $\begin{array}{l}\text { Well-watered mainly tilled plain, with some old vineyards. The land is rich in archaeological sites on both banks of the rive, } \\
\text { which was once navigable }\end{array}$ \\
\hline $\begin{array}{l}\text { LU 8. 'Macconi' of } \\
\text { Gela }\end{array}$ & $\begin{array}{l}\text { A sandy coastal strip, flat, with vast areas. of dunes. The landscape has been heavily modified by uncontrolled and disorderly } \\
\text { occupation of state land. There are greenhouses along the entire dune area, down the shoreline, and these have almost com- } \\
\text { pletely replaced the natural ecosystems and thus dramatically reduced the original habitats and biodiversity. }\end{array}$ \\
\hline $\begin{array}{l}\text { LU 9. Wetland of } \\
\text { Biviere di Gela Lake }\end{array}$ & $\begin{array}{l}\text { A lake flanking the coastal dunes, with large bights worming their way among the dunes. The banks are intensely cultivated, } \\
\text { with vineyards and vegetable cultivation. Of great natural value because of the diversified environments, which host several } \\
\text { animal species and ensure the survival of different food chains. Recognized as an internationally important wetland (Ramsar } \\
\text { convention) and special conservation area according to EEC directive } 79 / 409 \text {. }\end{array}$ \\
\hline $\begin{array}{l}\text { LU 10. Wetland of } \\
\text { Piana del Signore }\end{array}$ & $\begin{array}{l}\text { The area between Gela's industrial area, the oil refinery and Macconi greenhouses. An aquatic area with marshes, the River } \\
\text { Valle Priolo and a coastal strip), but major environmental problems due to human activities. The land is mainly flat. }\end{array}$ \\
\hline $\begin{array}{l}\text { LU 11. Gela River } \\
\text { Estuary }\end{array}$ & $\begin{array}{l}\text { A flat urbanized area with housing and a communication network which links Gela with the industrial plants located east of } \\
\text { the town. A quite natural river environment, although channelled between embankments at its estuary, with vegetation and } \\
\text { uncultivated areas on the banks. The mouth of the River Gela mouth is also rich in archaeological sites, mainly of Greek } \\
\text { origin. }\end{array}$ \\
\hline LU 12. Arena Hill & $\begin{array}{l}\text { Rather well conserved coastal dunes, despite large areas of the gulf being built over with houses and greenhouses. At Monte } \\
\text { Lungo, sheer marble cliffs face the sea. }\end{array}$ \\
\hline LU 14. Manfria Dun & $\begin{array}{l}\text { An ample dune sandbar, in some parts still well conserved, with hygrophilous, shrubby, herbaceous vegetation and various } \\
\text { rare or threatened species. The area is crossed by the Desusino, Rizzuto and Comunelli torrents }\end{array}$ \\
\hline
\end{tabular}

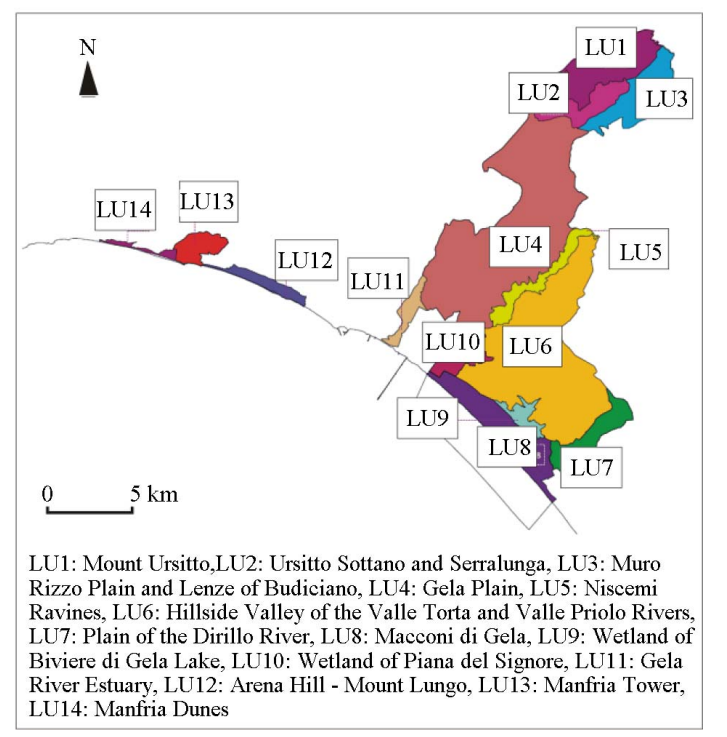

Figure 2. Landscape Unity (LU).

change.

Evaluating landscape capacity means defining a clear and reproducible program with precise evaluation criteria, and compensating for subjectivity in the evaluation. 
Following the suggestions in the LCA guide [37], the program had three phases:

- first phase, defining the evaluation criteria;

- second phase annotation of the evaluations;

- third phase evaluating landscape capacity.

In the first phase landscape capacity was evaluated following the guidelines in the literature [40,41], according to which evaluation must take into account:

- Landscape Value

- Landscape Quality/Condition

- Landscape Sensitivity

According to the LCA manual [37]:

The Value of each landscape depends on its local and regional context. It can be determined by establishing a consensus on its value, the sustainability criteria, and definitions of the identity of the place [37].

The quality or condition of the landscape is its integral physical condition and the visual, functional and ecological importance of each component.

There are many definitions of Landscape sensitivity and these definitions often conflict with one another. However if we define it as the stability of the characteristics of the landscape, it can be seen as: "the degree to which that character is robust enough to continue and to be able to recuperate from loss or damage. A landscape with a character of high sensitivity is one that, once lost, would be difficult to restore; a character that, if valued, must be afforded particular care and consideration in order for it to survive." [42].

Landscape sensitivity can either be analysed globally or in relation to specific cases or specific pressure, as is the case in the present study.

Different methods can be used to evaluate sensitivity [37]. This study combines analysis of character sensitivity and visual sensitivity.

As can be seen in Table 2, the qualitative characteristics for each evaluation component of landscape capacity have been given one of three values: low, medium or high. The evaluation criteria follow the indications in the literature, and in particular the French and German manuals [8], as well as some Italian regional manuals [43, 44].

In the second phase judgements based on the previously established evaluation criteria (character sensitivity, visual sensitivity, landscape quality and landscape value) were included in the appropriate dossier (Figure 3). It included a synthetic but efficacious structured and up-todate description of the character of the site, the structures it contained, and the various values which could be given to them. This allowed us to explain the criteria to the decision makers and the firms in an efficient way [33]. The information in Table 2 was used to give a value to each Landscape Unity (LU).

In the third phase the data from the evaluation of the different criteria were compared, in order to reach a definition of landscape capacity.

There are different ways of doing this. In this work we preferred to use a qualitative method which reported oral evaluations, using the criteria described in Table 2. These were then combined in a single matrix. The oral evaluations were converted into colours, so that the results would be clearly visible on the map.

The oral evaluations were divided into a five level scale: low, medium-low, medium, medium-high, and high. This simplified the process of combining the different evaluations and improved our ability to differentiate between the various areas.

Thus the evaluation process for each criteria was presented visually and comprehensibly, and it could be examined by, and shared with, the competent authorities [41].

An LU's capacity to host a photovoltaic park was high if its character sensitivity and landscape value were low. This meant that a photovoltaic park would not cause significant changes in the LU. The capacity was low if sensitivity and landscape value were high. This meant that a photovoltaic park would significantly alter the LU, and thus was inadvisable.

\section{Results}

Physical and perceptive criteria were used to determine the sensitivity of the characteristics of the landscape. This was combined with the visual sensitivity criteria and the value of the landscape in order to define the capacity.

\subsection{Character Sensitivity}

Character sensitivity was evaluated using the criteria described in Table 2.

All the LU had high sensitivity of natural character (SNC) because they contained protected habitats and species. This included LU 8, where there were only small areas of habitat, but precisely for that reason, these were of great value.

However there were very high levels of pollution in LU 8, because of the many greenhouses, and this, combined with permeable soil and high agricultural value meant that the LU was defined as medium sensitivity in our survey. Character sensitivity is, indeed, greatly influenced by the landscape quality and in LU 8 this was very low.

LU 8, 10, 11, were given low human sensitivity characteristics (HSC) because parts of them were used for intensive agriculture (LU 8) or industry (LU 10 and 11). Building photovoltaic parks would not modify the productive functions of the landscape. LU 12 had areas of traditional hillside agriculture, used for dry arable farming, and also tourist structures in its lower areas along the 
Table 2. Definitions of the criteria for evaluating the sensitivity of the character, the visual sensitivity, the landscape quality and the landscape value for evaluating the capacity of the landscape.

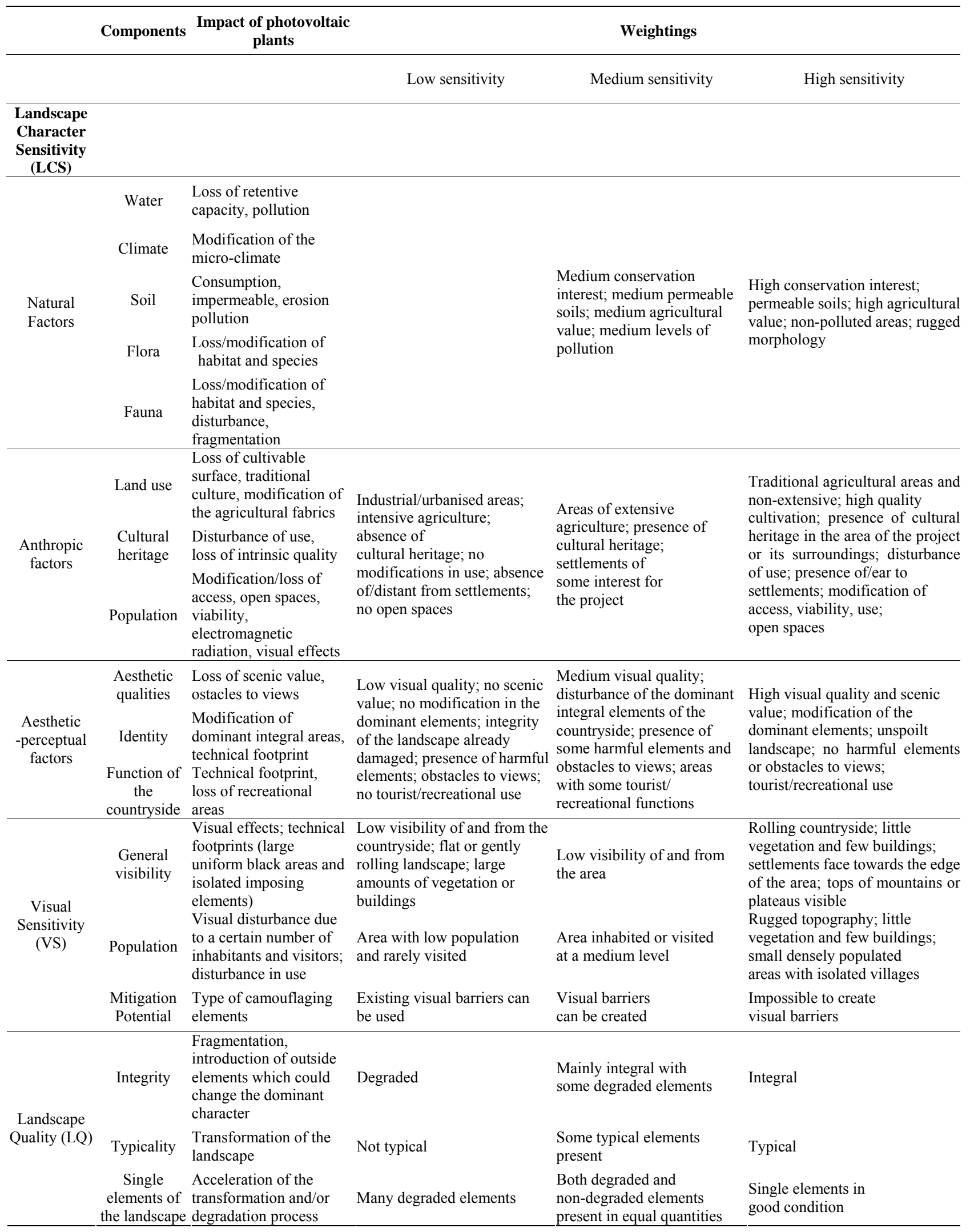


Continued

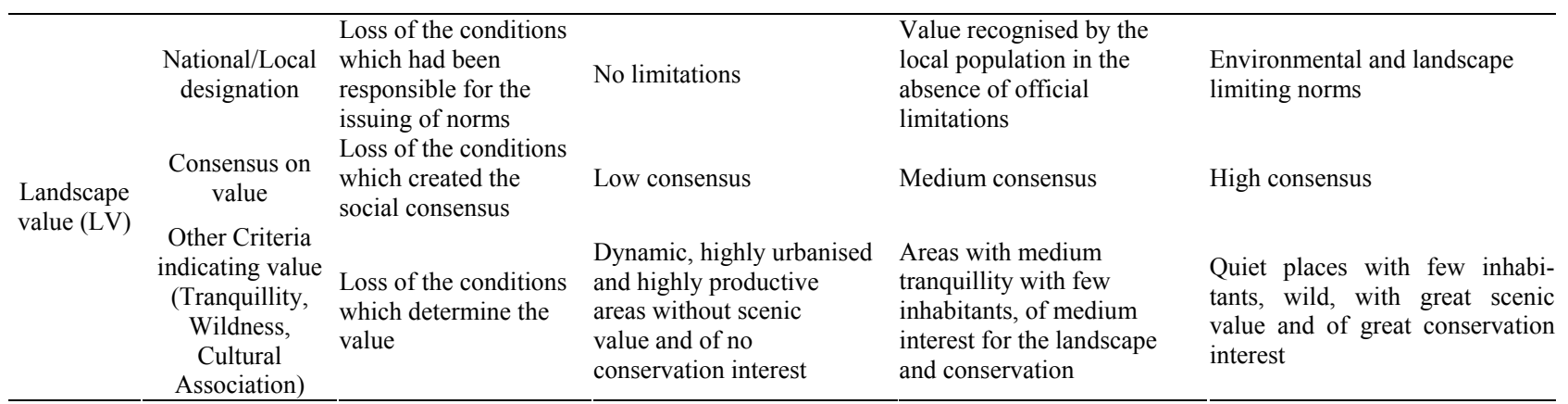

coast. Thus this LU was given medium levels of sensitivity in its human and cultural characteristics. LUs 1, 5, 9, 13 and 14 had high sensitivity, because there were no settlements and there was valuable historical patrimony. LUs 2, 3, 4, 6 and 7 had high sensitivity because they contained settlements and traditional agriculture, and also because they contained, or were near to, certain areas of historical or archaeological importance. The traditional rural character of these LUs was very high. However most of the valuable rural buildings are in ruins, as are the archaeological sites and the numerous historical remains, and are not marked on maps, and there are also certain elements present which damage the landscape.

The Sensitivity of the Aesthetic and Perceptual Characteristics (SPC) was found to be high for LUs 1, 5, 9, 12, 13 and 14, where natural characteristics prevail. These are silent peaceful places where one feels a great sense of solitude. LUs 12 and 13 have beautiful views over the plain of Gela and the sea. Building photovoltaic parks in such places would damage the landscape and distort their perceived characteristics.

LUs 2, 3, 6 and 7 have high sensitivity due to the tranquillity of the agricultural landscape, with a prevailing sense of the balance with nature, of remoteness, and of the unchanging quality to the landscape.

LU 4 is dominated by Castello Svevo on a limestone hill. The rural landscape is wide and open. The slopes of the Niscemi plateau, which can be seen to the east of the $\mathrm{LU}$, are of great scenic value. The colours of the area change with the seasons, because it is used for cereal crops, and so in summer it becomes yellow, which would contrast greatly with the colours of potential photovoltaic parks. Consequently this is a high sensitivity area.

The very low levels of SPC for LU 8 and 11 are because there are many negative factors. LU 8 is dominated by the greenhouses which block every view of the surrounding landscape and also by piles of discarded plastic and illegal rubbish dumps.

In LU 11, by contrast, the panorama is destroyed by the chaotic diffusion of industrial buildings and their infrastructure. LU 10 has some natural characteristics, alongside industrial plants and many negative factors for the landscape. For this reason it has medium sensitivity.

To determine the overall sensitivity of the character one must take the landscape quality into consideration. The evaluation criteria for this are reported in Table 2.

LUs 1, 2, 3, 4, 9 and 14 have high landscape quality, because they contain relatively unspoiled valuable natural habitats (LUs 1, 9 and 14) or because they are typical of the local rural characteristics of the area (LUs 2, 3 and 4). However greenhouses are beginning to be built in LU 14. LUs 12 and 13 have a mainly unspoilt quality, although there are some recent buildings which do not blend into the landscape. LUs 8,10 and 11 are of low landscape quality, because of the great impact of human activities. This has resulted in natural resources being damaged, the beginning of loss of biodiversity, and reductions in the social quality of life, as well as the ability of the local population to identify with the area. The remaining LUs have medium values, because, although they are in relatively good condition, they are less typical of the area than are the other LUs.

Information on evaluating the natural, human, and perceptive character were combined with the quality of each landscape (Figure 4), to create a map of the overall character sensitivity (Figure 5). Clearly, the character sensitivity of each LU is greatly influenced by its quality. For example LU 8 has low sensitivity because all the parameters are low.

\subsection{Visual Sensitivity}

The criteria for determining visual sensitivity are shown in Table 2.

LUs $1,5,7$ and 14 have higher visual sensitivity than those on hilly land (LUs 1, 5 and 14) and one cannot change this, even though the landscape is not much used (Figure 6). LUs 2 and 3 have views over the plain of Gela and the Niscemi plateau, and so have high visual sensitivity. LU 10 has high sensitivity because, although not of highly visible, it is frequently used by local people. The same is true for LU 11. LU 8 has low sensitivity because it is can only rarely be glimpsed from the main roads, and because some of the structures of a solar park 


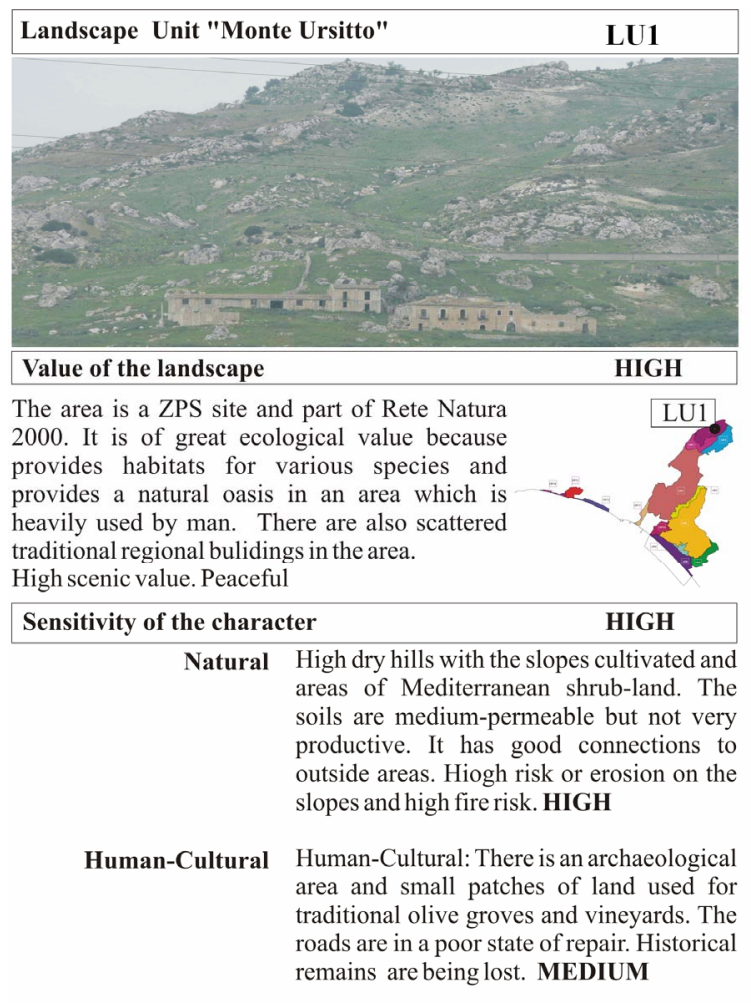

Aesthetic-perceptive Aesthetic-perceptive: there is a feeling of unspoilt nature, with peaceful quiet places and a sense of isolation with white rocky outcrops alternating with green vegetation. The character of the country is accentuated. Closeknit countryside with limited visibility alternates with expansive views of the surrounding areas. HIGH

\begin{tabular}{|cl|} 
Landscape Quality & HIGH \\
\hline Visual Sensitivity & \multicolumn{1}{c|}{ MEDIUM } \\
\hline Visibility & $\begin{array}{l}\text { The area is almost uninhabited with a few } \\
\text { scaltered buildings. There is a liunting } \\
\text { reserve. It can be seen from the the town } \\
\text { of Niscemi on the nearby plateau. LOW }\end{array}$ \\
Mopography & Rugged. HIGH \\
Mitigation measures & $\begin{array}{l}\text { Reasonably effective. With an appropriate } \\
\text { plan it would be little visible from nearby, } \\
\text { but would remain visible from the Niscemi } \\
\text { plateau. MEDIUM }\end{array}$ \\
\hline
\end{tabular}

Figure 3. Evaluation dossier.

would have less visual impact than the existing greenhouses. The remaining LU were classified as medium sensitivity because they are rarely visited (LU 12) and/or because it would be possible to mitigate the effects of the parks (UPs 4 and 6).

\subsection{The Value of the Landscape}

The landscape's value was generally determined on the basis of its institutional or social importance and its rare and high biodiversity.

The evaluation criteria were closely connected to the specific area, which is of great conservation interest but also suffers from important human impact. Thus it was decided to give additional weight to the remaining nature, to the sense of peacefulness, and to the scenery.

No LU had a landscape value of less than medium, defined as their importance for conserving biodiversity, as sites of the Natura 2000 network. LU 9 (Lake Biviere) had a very high value, because it is an internationally important wetland, of great importance for bird protection (Ramsar Convention), and of regional importance as the largest coastal lake. This LU is, furthermore, an oasis of unspoiled nature and peace. 


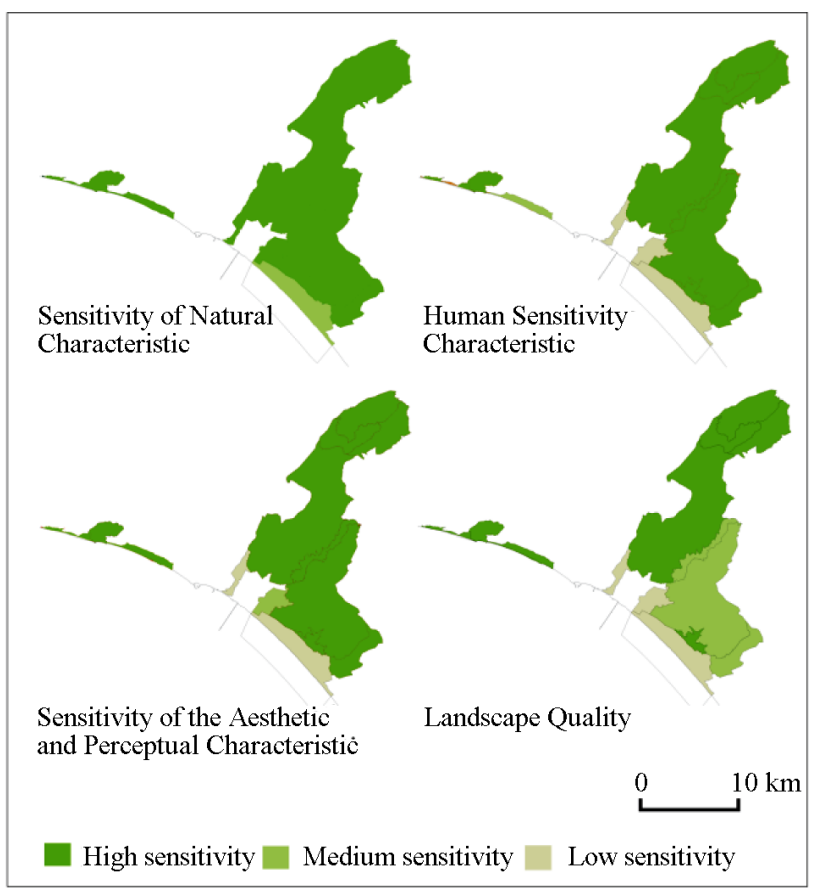

Figure 4. Sensitivity of natural, human, perceptive character and quality sensitivity of landscape.

SNC Sensitivity of Natural Characteristics

HSC Human Sensitivity Charaacteristics

SPC Sensitivity of the Aesthetic and Perceptual Charaacteristics

LQ Landscape Quality
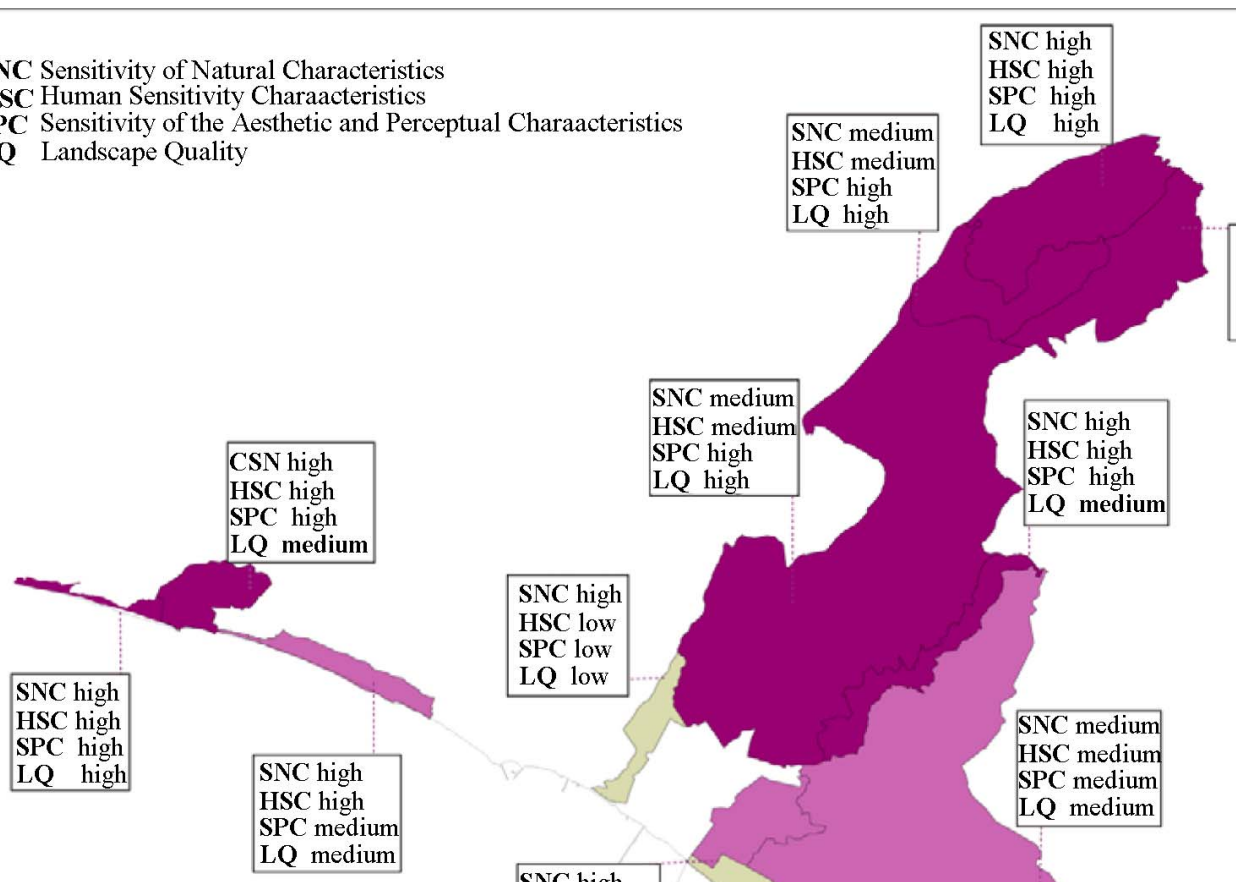

SNC medium HSC medium

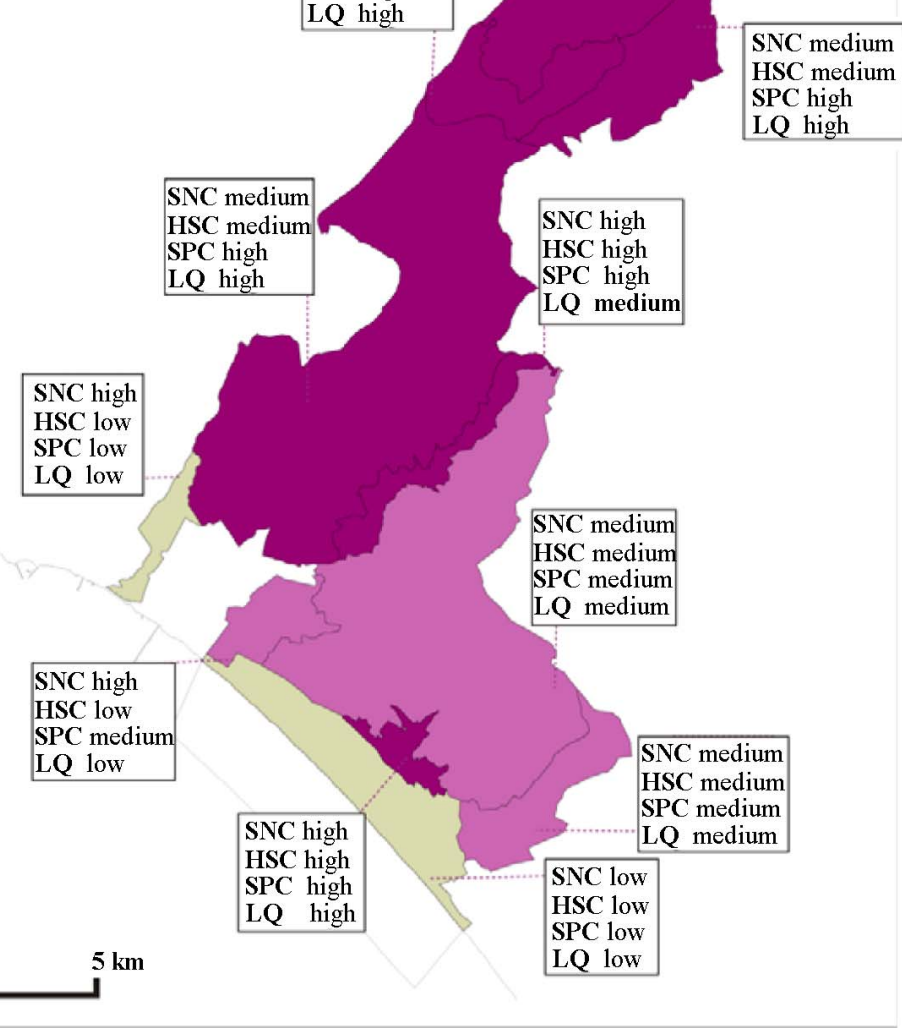

Figure 5. Overal sensitivity of the character. 
The coastal LUs 6, 8,11,12, 13 and 14, were given high ratings because of their importance as links between land and sea biospheres. They also include the mouths of the rivers which cross the SCI/SPA site. LUs 8, 12, 13 and 14 also contain fragile dune systems which need conservation. LU 13 contains important historical architecture and archaeological remains. The transient bogs of LU 10 and the riverside areas of LU 7 are also of high value. LUs 2, 4 and 5 are homes to the typical bird species which live in the semi-steppe cereal growing areas. LU 1 is of great value for conserving habitats and species and is a natural oasis in an area with intense human activities. It also contains traditional rural buildings and beautiful scenery.

\subsection{Landscape Capacity}

The landscape capacity was defined by comparing the results for the character sensitivity (LCS), and the visual sensitivity and combining these with the landscape value, using the correlation criteria suggested in the LCA manuals (Table 3). The landscape capacity map shows the values given to the different components for each $\mathrm{LU}$ (Figure 7).

Because landscape capacity depends on the values given to the landscape, no LU was found to be highly suitable for hosting a photovoltaic park. Indeed all the LUs had high landscape values, because of their importance for conservation. However LU 8 is greatly degraded and thus was given a medium-high capacity.

LUs $1,9,10$ and 14 had low capacity mainly because of the rarity of their environments. LUs 7 and 11 had low levels because of their importance as ecological link areas.

LUs 2, 3, 4 and 5 had low capacity because they are typical examples of steppe and cereal cultivation, and the homes of rich bird-life, which is why this area is a Natura 2000 site. These LUs are also very visible, and so any

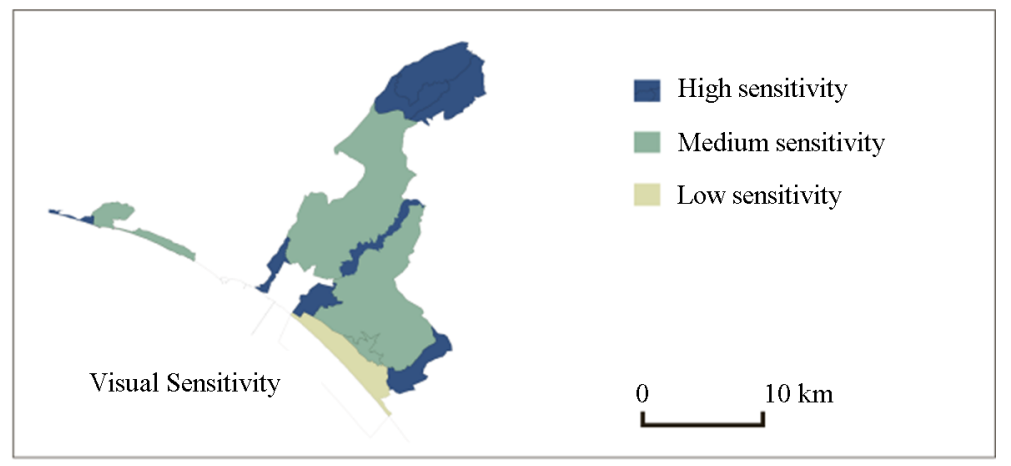

Figure 6. Visual Sensitivity.

Table 3. Evaluation of the landscape capacity.

\begin{tabular}{ccccccccc}
\hline Landscape Unit & SNC & HSC & SPC & LQ & LCS & VS & LV & Landscape Capacity \\
\hline LU 1 & High & High & High & High & HIGH & High & High & LOW \\
LU 2 & Medium & Medium & High & High & MEDIUM & Medium & High & LOW \\
LU 3 & Medium & Medium & High & High & MEDIUM & Medium & High & LOW \\
LU 4 & High & Medium & Medium & High & MEDIUM & Medium & High & LOW \\
LU 5 & High & High & High & Medium & HIGH & High & High & LOW \\
LU 6 & Medium & Medium & Medium & Medium & MEDIUM & Medium & High & MEDIUM-LOW \\
LU 7 & Medium & Medium & Medium & Medium & MEDIUM & High & High & LOW \\
LU 8 & Low & Low & Low & Low & LOW & Low & High & MEDIUM-HIGH \\
LU 9 & High & High & High & High & HIGH & Medium & High & LOW \\
LU 10 & High & Low & Medium & Low & MEDIUM & High & High & LOW \\
LU 11 & High & Low & Low & Low & MEDIUM & High & High & LOW \\
LU 12 & High & Low & Medium & Medium & MEDIUM & Medium & High & MEDIUM-LOW \\
LU 13 & High & High & High & Medium & HIGH & Medium & High & MEDIUM-LOW \\
LU 14 & High & High & High & High & HIGH & High & High & LOW \\
\hline
\end{tabular}

SNC: Sensitivity of natural characters; HSC: Sensitivity of Human characters; SPC: Sensitivity of Aesthetic-perceptual Character; LQ: Landscape quality; LCS: Landscape characters sensitivity; VS: Visual sensitivity; LV: Landscape Value. 


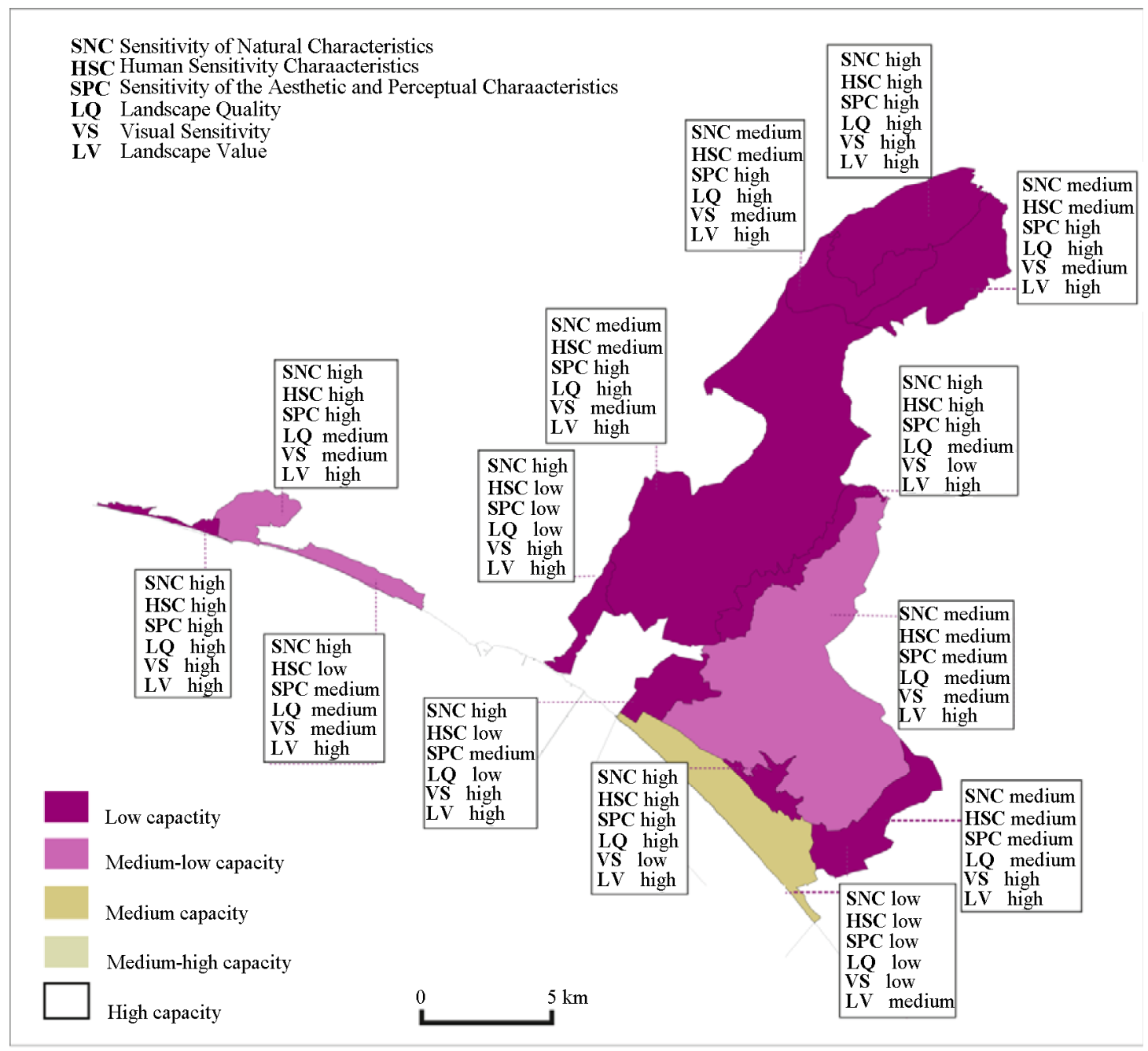

Figure 7. Capacity.

new structures immediately strike the eye.

The remaining LU has medium capacity, because of their high value, even when they have low sensitivity.

\section{Discussion}

No LU was found to be suitable for change, and, generally speaking, high impact technology such as solar panels should not be introduced. However it was discovered that even protected areas contain degraded landscape, and these have medium-high capacity for transformation, if the impact of the project is verified occasionally. It was also found that low capacity was linked to high character sensitivity and visual sensitivity, and not merely to the high values given to the landscape.

With reference to the method used for evaluating the sensitivity of the landscape and its capacity to host a photovoltaic park, we would like to highlight the following points.

The evaluation of the capacity of the landscape is based on the literature on landscape characteristics and is in line with the principles of the European Landscape Convention (art. 1).

There were certain subjective elements in the evaluation but, if accepted as part of a transparent, simple and rigorous process, with clearly established evaluation criteria, and one which is easily comprehensible to laymen, they could become a key way of involving citizens in territorial planning, allowing them to direct the changes in their homeland. The qualitative weightings in the evaluation were developed in a single matrix. This summed up the results of the different phases and allowed the steps taken to be retraced and the reasoning behind the final proposals to be understood. In the approach used "capacity" did not define the precise limits for development in a particular landscape but, instead, indicated the landscape's ability to host the changes, identifying those highly sensitive aspects of the landscape whose alteration would change the significance of the landscape.

A decisive ironclad weighting was given to values attributed to the landscape when evaluating its capacity, 
and these values were, in any case, high in protected areas. It is however desirable that such values emanate from the involvement of the local population.

Further research could test the suitability of the evaluation method for different types of pressure, either in the same place or in different locations, with specific evaluation criteria being defined for each case.

\section{Conclusions}

This paper tested the appropriateness of the methods in the LCA manuals of the Countryside Agency and Scottish Natural Heritage for evaluating the capacity of a protected landscape to assimilate the modifications that building a solar park would cause at the Natura 2000 site "Torre Manfria, Biviere di Gela, Piana di Gela.

The work showed how effective the British system is for analysing the characteristics of the landscape and how its evaluation system could identify areas suitable for specific human developments.

The research focused on the effect that solar parks would have on the landscape [8], and identified reference criteria and useful weightings for the relevant factors in the evaluation process. These followed the principles established by the ELC for evaluating particular landscapes. The work identified their characteristics, and then added a "specific measure" which gave value to the landscape, based on its importance to the local population.

This evaluation process may also be used for a landscape which had already been examined by specific landscape planning instruments. The evaluation process is designed to protect biodiversity, to conserve natural resources and to create new and different management criteria for rural areas, which will encourage sustainable development or mitigate the impact of human activities, verifying whether or not the areas are suitable for photovoltaic parks.

In conclusion, we believe that evaluating the capacity of the landscape based on an analysis of its characteristics is an important planning instrument, and that the results of such evaluations should be widely communicated, in particular to the local administrations that are responsible for landscape planning. This would improve the planning of human activities in rural areas and pinpoint the most suitable areas for such activities.

Finally, it is worth mentioning that even when a protected environment has a high capacity for hosting new plants, the effective capacity depends on the specific project. Every form of intervention affects the landscape, and the impact depends on the amount of change and possible mitigating actions. Although attempts may be made to reduce them, the effects can still be significant and are always related to the specific context and the characteristics of the new structures [40]. Thus, the signifi- cance can only be evaluated on a case by case basis.

\section{Acknowledgements}

This paper has been prepared within the project LIFE11 NAT/IT/232, funded by the European Union.

\section{REFERENCES}

[1] GSE-Gestore Servizi Energetici, "Rapporto Statistico 2011, Solare Fotovoltaico (Statistical Report on Photovoltaic Parks)," 2012.

http://www.gse.it/it/Dati\%20e\%20Bilanci/Osservatorio\% 20statistico/Pages/default.aspx

[2] A. Evans, V. Strezov and T. J. Evans, "Assessment of Sustainability Indicators for Renewable Energy Technologies," Renewable and Sustainable Energy Reviews, Vol. 13, 2009, pp. 1082-1088.

http://dx.doi.org/10.1016/j.rser.2008.03.008

[3] T. L. Neff, "The Social Costs of Solar Energy: A Study of Photovoltaic Energy Systems (Pergamon Policy Studies on Science and Technology," Pergamon Press, New York, 1981.

[4] V. Vahro, "Environmental Impact of Photovoltaic Electrification in Rural Areas," Energy and Environment, Vol. 13, 2002, pp. 81-104. http://dx.doi.org/10.1260/0958305021501092

[5] J. Zoellner, P. Schweizer-Ries and C. Wemheuer, "Public Acceptance of Renewable Energies: Results from Case Studies in Germany," Energy Policy, Vol. 36, No. 11, 2008, pp. 4136-4141.

[6] P. Bonfanti, A. Fregonese and M. Sigura, "Landscape Analysis in Areas Affected by Land Consolidation," Landscape Urban Planning, Vol. 37, 1997, pp. 91-98. http://dx.doi.org/10.1016/S0169-2046(96)00373-8

[7] R. Chiabrando, E. Fabrizio and G. Garnero, "The Territorial and Landscape Impacts of Photovoltaic Systems: Definition of Impacts and Assessment of the Glare Risk," Renewable and Sustainable Energy Reviews, Vol. 13, No. 8, 2009, pp. 2441-2451. http://dx.doi.org/10.1016/j.rser.2009.06.008

[8] Meedaat, “Guide Sur la Prise en Compte de L'Environnement Dans les Installations Photovoltoiques au SolL'exemple Allemand," Ministère de l'Écologie, Parigi, 2009.

http://www.photovoltaique.info/IMG/pdf/guide_du_MED DAAT_aspect_environnementale.pdf

[9] T. Tsoutsos, N. Frantzeskaki and V. Gekas, "Environmental Impacts from the Solar," Energy Policy, Vol. 33, 2005, pp. 289-296.

http://dx.doi.org/10.1016/S0301-4215(03)00241-6

[10] R. Chiabrando, E. Fabrizio and G. Garnero, "On the Applicability of the Visual Impact Assessment OAISPP Tool to Photovoltaic Plants," Renewable and Sustainable Energy Reviews, Vol. 15, 2011, pp. 845-850. http://dx.doi.org/10.1016/j.rser.2010.09.030

[11] A. C. Torres-Sibille, V. A. Cloquell-Ballester, V. A. Cloquell-Ballester and M. A. Artacho Ramırez, "Aesthetic 
Impact Assessment of Solar Power Plants: An Objective and a Subjective Approach," Renewable and Sustainable Energy Reviews, Vol. 13, No. 5, 2009, pp. 986-999. http://dx.doi.org/10.1016/j.rser.2008.03.012

[12] A. Di Bene and L. Scazzosi, "Gli Impianti Eolici: Suggerimenti per la Progettazione e la Valutazione Paesaggistica (Windfarms: Suggestions for Their Planning and the Value Given to the Landscape)," Gangemi Editore, Roma, 2006.

[13] A. Torres Sibille, V. Cloquell-Ballester, V. Cloquell-Ballester and R. Darton, "Development of a Multicriteria Indicator for the Assessment of Objective Aesthetic Impact of Wind Farms," Renewable and Sustainable Energy Reviews, Vol. 13, No. 1, 2009, pp. 44-55. http://dx.doi.org/10.1016/j.rser.2007.05.002

[14] G. Senes and A. Toccolini, "Tecniche per la Valutazione Della Qualità Visuale del Paesaggio Rurale (Techniques for Evaluating the Visual Quality of the Rural Landscape)," Rivista di Ingegneria Agraria, Vol. 4, 2006, pp. 7-14.

[15] T. Tsoutsos, A. Tsouchlaraki, M. Tsiropoulos and M. Serpetsidakis, "Visual Impact Evaluation of a Wind Park in a Greek Island," Applied Energy, Vol. 86, No. 5, 2009, pp. 1587-1600.

http://dx.doi.org/10.1016/j.apenergy.2008.08.013

[16] J. Hurtado, J. Fernandez, J. Parrondo and E. Blanco, "Spanish Method of Visual Impact Evaluation in Wind Farms," Renewable and Sustainable Energy Reviews, Vol. 8, No. 5, 2004, pp. 483-491.

http://dx.doi.org/10.1016/j.rser.2003.12.009

[17] B. Möller, "Changing Wind-Power Landscapes: Regional Assessment of Visual Impact on Land Use and Population in Northern Jutland, Denmark," Applied Energy, Vol. 83, No. 5, 2006, pp. 477-494. http://dx.doi.org/10.1016/j.apenergy.2005.04.004

[18] J. Hernandez, L. Garcia and F. Ayuga, "Assessment of the Visual Impact on the Landscape by New Buildings: A Methodology for Site Selection," Landscape Urban Planning, Vol. 68, 2004, pp. 15-28. http://dx.doi.org/10.1016/S0169-2046(03)00116-6

[19] L. Garcia, J. Hernandez and F. Ayuga, "Analysis of the Materials and Exterior Texture of Agro-Industrial Buildings: A Photo-Analytical Approach to Landscape Integration," Landscape Urban Planning, Vol. 74, 2006, pp. 110-124.

http://dx.doi.org/10.1016/j.landurbplan.2004.10.007

[20] R. Ryan, "Preserving Rural Character in New England: Local Residents' Perception of Alternative Residential Development," Landscape Urban Planning, Vol. 61, 2002, pp. 19-35. http://dx.doi.org/10.1016/S0169-2046(02)00066-X

[21] E. Rogge, F. Nevens and H. Gulinck, "Reducing the Visual Impact of 'Greenhouse Parks' in Rural Landscapes," Landscape and Urban Planning, Vol. 87, 2008, pp. 76-83. http://dx.doi.org/10.1016/j.landurbplan.2008.04.008

[22] M. Sevenant and M. Antrop, "Settlement Models, Land Use and Visibility in Rural Landscapes: Two Case Studies in Greece," Landscape Urban Planning, Vol. 80, 2007, pp. 362-374. http://dx.doi.org/10.1016/j.landurbplan.2006.09.004

[23] EU Council Directive, "2000 Network on the Conservation of Natural Habitats and of Wild Fauna," Council Directive 92/43/EEC, Vol. 1, 1992.

http://eurlex.europa.eu/LexUriServ/LexUriServ.do?uri=C ELEX:31992L0043:EN:NOT. Accessed 03.01.2012

[24] Q. Wang, H. Tang, J. Li, H. Ma, T. Cheng and X. Wang, "Spatial and Dynamic Analysis of Regional Sustainable Development Using Geographic Information System and Relative Carrying Capacity of Resources," Natural Resources, Vol. 2, 2011, pp. 28-34. http://dx.doi.org/10.4236/nr.2011.21005

[25] S. Fazal1, S. C. M. Geertman and F. J. Toppen, "Interpretation of Trends in Land Transformations-A Case of Green Heart Region (The Netherlands)," Natural Resources, Vol. 3, 2012, pp. 107-117. http://dx.doi.org/10.4236/nr.2012.33015

[26] Council of Europe, "European Landscape Convention," 2000 .

http://conventions.coe.int/Treaty/Commun/QueVoulezVo us.asp? $\mathrm{NT}=176 \& \mathrm{CL}=\mathrm{ENG}$

[27] E. Salizzoni, "Paesaggi Protetti, Laboratori di Sperimentazione per il Paesaggio Costiero Mediterraneo ("Protected Landscapes" an Experimental Laboratory for the Mediterranean Coastal Landscape)," III Simposio, Il Monitoraggio Costiero Mediterraneo: Problematiche Tecniche di Misura (Third Symposium on Monitoring the Mediterranean Coast. Technical Measurement Problems), Livorno, 2010.

[28] P. Minissale, S. Sciandrello, L. Scuderi and G. Spampinato, "Gli Ambienti Costieri Della Sicilia Meridionale (the Coastal Environment of Southern Sicily)," Bonanno Editore, Roma, 2010.

[29] S. Brullo and S. Sciandrello, "La Vegetazione Lacustre del Biviere di Gela (Lake Vegetation of Biviere di Gela," Fitosociologia, Vol. 43, No. 2, 2006, pp. 21-40.

[30] R. Mascara and M. Sarà, "Censimento di Specie D'Uccelli Steppico-Cerealicole D'Interesse Comunitario Nella Piana di Gela (Cereal Crop Bird Census of Community Interest in the Gela Plain)," Naturalista Sicil, Vol. 1-2, 2007, pp. 27-39.

[31] LIPU, "Site Management Plan of SCI-SPA Torre Manfria, Biviere di Gela, Plain of Gela and Seafront Area,” 2009. http://www.riservabiviere.it/progetti.asp?idn=195\&titolo= Piano+Gestione+Biviere+Macconi+documenti

[32] P. Russo, L. Carullo, L. Riguccio and G. Tomaselli, "Identification of Landscapes for Drafting Natura 2000 Network Management Plans: A Case Study in Sicily," Landscape and Urban Planning, Vol. 101, 2011, pp. 228-243. http://dx.doi.org/10.1016/j.landurbplan.2011.02.028

[33] L. Scazzosi, "Landscape and Cultural Landscape: European Landscape Convention and UNESCO Policy," In: UNESCO World Heritage Centre, Ed., Cultural Landscapes: The Challenges of Conservation, 2003, pp. 55-59. http://unesdoc.unesco.org/images/0013/001329/132988e. pdf

[34] Å. Ode, M. S. Tveit and G. Fry, "Capturing Landscape Visual Character Using Indicators: Touching Base with 
Landscape Aesthetic Theory," Landscape Research, Vol. 33, No. 1, 2008, pp. 89-117.

http://dx.doi.org/10.1080/01426390701773854

[35] ECOVAST (European Council for the Village and Small Town), "Landscape Identification. A Guide to Good Practice," 2006.

http://www.ecovast.org/english/publications_e.htm

[36] C. Swanwick, "Landscape Character Assessment, Guidance for England and Scotland," The Countryside Agency and Scottish Natural Heritage, 2002.

http://www.heritagecouncil.ie/fileadmin/user_upload/Plan ning/LCA_CPD/LCA_CPD_Sep_2011/Reports/LCA_Gu idance_for_England_and_Scotland.pdf

[37] C. Swanwick, "Topic Paper 6: Techniques and Criteria for Judging Capacity and Sensitivity," The Countryside Agency and Scottish Natural Heritage, 2003. http://www.naturalengland.org.uk/Images/lcatopicpaper6 tcm6-8179.pdf

[38] M. Jacobs, "Making Sense of Environmental Capacity," Council for the Protection of Rural England, London, 1997.

[39] H. S. D. George, "The Limits of Acceptable Change (LAC) System for Wilderness Planning," Department of Agriculture, Forest Service, Intermountain Forest and Range Experiment Station, Ogden, 1985.

[40] J. Benson, K. Scott, C. Anderson, R. Macfarlane, H. Dunsford and K. Turner, "Landscape Capacity Study for Onshore Wind Energy Development in the Western Isles," Scottish Natural Heritage, Commissioned Report No. 042 -ROAME No. F02LC04, 2004. http://www.snh.org.uk/pdfs/publications/commissioned r eports/ReportNo042A.pdf Accessed 01.08.2012.

[41] A. Grant, P. Clarke and S. Lynch, "Landscape Capacity Studies in Scotland-A Review and Guide to Good Practice" Scottish Natural Heritage, Commissioned Report No. $385,2010$.

http://www.snh.org.uk/pdfs/publications/commissioned_r eports/385.pdf

[42] C. Bray, "Unpublished Paper on a County Wide Assessment of Landscape Sensitivity," 2003.

http://www.naturalengland.org.uk/Images/lcatopicpaper6 _tcm6-8179.pdf

[43] Regione Autonoma Della Sardegna, "Linee Guida per L'individuazione Degli Impatti Potenziali Degli Impianti Fotovoltaici e Loro Corretto Inserimento nel Territorio (Guidelines for Identifying the Potential Impact of Photovoltaic Parks and Their Insertion into the Landscape)," 2008.

http://www.regione.sardegna.it/documenti/1_74_2008062 4174706.pdf

[44] Regione Lombardia, "Linee Guida per L'Autorizzazione di Impianti per la Produzione di Energia da Fonti Energetiche Rinnovabili (Fer) - Impianti Fotovoltaici ed Eolici e per la Valutazione Ambientale Degli Stessi Impianti (Guidelines for Authorising Plants for the Production of Energy from Renewable Energy Sources (Fer)-Photovoltaic Parks and Wind Farms, and for Evaluating Their Environmental Impact), 2009.

http://www.territorioambiente.com/normativa/pdf/fontirin novabili/2012\%20Linee\%20Guida\%20FER.pdf 